\title{
CONFERÊNCIA DAS EDIÇÕES FILOLÓGICAS DO DIÁRIO DE UM JOÃO NINGUÉM E LÁGRIMAS DO ESCRITOR EULÁLIO MOTTA
}

\author{
Jamille Santos Marques ${ }^{1}$; Liliane Lemos Santana Barreiros ${ }^{2}$ \\ 1. Bolsista PIBIC/FAPESB, Graduanda em Letras com Espanhol, Universidade Estadual de Feira de Santana, \\ e-mail: jamillesatmarques@gmail.com \\ 2. Orientadora, Departamento de Letras e Artes, Universidade Estadual de Feira de Santana, e-mail: \\ lilianebarreiros@hotmail.com
}

PALAVRAS-CHAVE: Edição; Cadernos; Eulálio Motta.

\section{INTRODUÇÃO}

O escritor baiano Eulálio Motta (1907-1988) organizou um acervo que compõe diversos tipos de documentos. Esse conjunto documental destaca-se por apresentar 15 cadernos que concentram a maior produção inédita de Eulálio Motta. Além disso, vale ressaltar que esses cadernos se referem ao laboratório do escritor e integram o corpus principal do projeto Edição das Obras Inéditas de Eulálio Motta - IV Etapa (UEFS/CONSEPE N. 070/2016) que prevê a edição e estudo dos documentos do escritor, visando à edição de suas obras inéditas. Com base nisso, o plano de trabalho 2018/2019 PIBIC/FAPESB propôs a conferência das transcrições dos textos dos cadernos Diário de um João Ninguém e Lágrimas.

A conferência das transcrições dos cadernos Diário de um João Ninguém e Lágrimas proposta no plano de trabalho objetivou seguir os critérios e os princípios adotados na metodologia do referido projeto de pesquisa, priorizando uma edição criteriosa de todos os elementos que os textos apresentam (interpolações, lapsos do autor, ortografia, acentuação entre outros). Esse rigor fez-se necessário para possibilitar futuros estudos através das edições dos textos dos cadernos conferidos.

A conferência da transcrição é imprescindível para a evitar erros na reprodução. Todo editor está sujeito a erros, por isso mesmo, na edição de um texto é importante lançar mão de procedimentos de conferência da transcrição dos textos, sendo importante envolver sujeitos diferentes nesse processo para evitar, na medida do possível, erros na transcrição. Segundo Cambraia (2005), um erro cometido numa edição propaga informações que se cristalizam na sociedade, sendo difícil desfazer certos equívocos. Para Barreiros (2016), muitas vezes, o filólogo tem contato com documentos de acervos de escritores e os leitores só tem acesso ao texto por meio da edição preparada pelo filólogo, portanto, o rigor na transcrição do texto é uma condição sine qua non para que o resultado da edição tenha credibilidade científica.

Segundo Barreiros (2012), a edição de um texto é uma tarefa que mobiliza diversos conhecimentos. O texto precisa ser compreendido em seus aspectos linguísticos, históricos e socais. É preciso conhecer o código e os usos escribendis do autor, a história de sua transmissão e recepção, e as técnicas empregadas para sua codificação. Portanto, editar um texto não é uma tarefa simples e que pode ser feita de modo apressado. Nesse sentido, o trabalho realizado contribui efetivamente para a agenda de atividades previstas no âmbito do Projeto de Pesquisa Edição das Obras Inéditas de Eulálio Motta.

\section{METODOLOGIA}

Para realizar a conferência da transcrição do corpus do plano trabalho foi adotado o critério de edição semidiplomática. Nesse tipo de edição, conserva-se a escrita do autor, apenas desenvolve-se as abreviaturas e sinaliza-se com símbolos os 
acontecimentos textuais. Telles (2012, p.139) afirma que: "Com esse tipo de edição, pretende-se possibilitar o acesso e a preservação do texto editado, a partir de critérios que restituirão e fixarão a sua forma genuína, garantindo a fidedignidade e a acessibilidade necessárias". Sendo assim, para fundamentar a pesquisa na perspectiva teórico-metodológica foram utilizados como referências: Spina (1977), Cambraia (2005), Carvalho (2012), Telles (2012) e Barreiros (2012; 2013).

Os critérios de transcrição utilizados têm por finalidade conservar as características da escrita dos textos presentes nos cadernos Diário de um João Ninguém e Lágrimas. A saber:

- No caso de manuscritos encadernados, indica-se a folha, à margem direita, exemplo: (f. $1 \mathrm{r}$ ou f.1v);

- As linhas são numeradas de 5 em 5 à margem esquerda;

- Os textos são transcritos em fonte Times New Roman padrão Word; de tamanho 11, justificados à margem esquerda;

- Transcreve-se o título como se encontra no original;

- A rubrica do autor indica-se entre colchetes;

- São mantidas as interpolações, os lapsos do autor, a ortografia, a acentuação, o uso de maiúsculas, a pontuação e registraram-se todas as correções, emendas, rasuras e acréscimos, através da utilização de símbolos;

- A edição corresponde a uma transcrição linearizada acomodando as rasuras, substituições, correções e acréscimos na sequência lógica do texto (não obedecendo a topografia do original).

Dos símbolos utilizados para indicar fenômenos no texto, são eles:

1. \{ \} seguimento riscado, cancelado;

2. $\{\dagger\}$ seguimento ilegível;

3. $\{\dagger\} /$ segmento ilegível substituído por outro legível na relação \{ilegível \} /legível\;

4. \{ \} / substituição por sobreposição, na relação \{substituído\} /substitutol;

5. \{ $\{[\uparrow]$ riscado e substituído por outro na entrelinha superior;

6. \{ $\{[\downarrow]$ riscado e substituído por outro na entrelinha inferior;

7. \{\}$[\rightarrow]$ riscado e substituído por outro na margem direita;

8. \{\}$[\leftarrow]$ riscado e substituído por outro na margem esquerda;

9. [ ] acréscimo no curso da linha;

10. $[\uparrow]$ acréscimo na entrelinha superior;

11. $[\downarrow]$ acréscimo na entrelinha inferior;

12. $[\rightarrow]$ acréscimo na margem direita;

13. $[\leftarrow]$ acréscimo na margem esquerda;

14. $[\uparrow\{\}]$ acréscimo na entrelinha superior riscado;

15. $[\uparrow\{\uparrow\}]$ acréscimo na entrelinha superior ilegível;

16. $[\uparrow\{\} / \backslash]$ acréscimo na entrelinha superior riscado e substituído por outro na sequência;

17. $[\uparrow\{\uparrow\} / \backslash]$ acréscimo na entrelinha superior ilegível e substituído por outro na sequência;

18. $[\downarrow\{\}]$ acréscimo na entrelinha inferior riscado;

19. $[\downarrow\{\dagger\}]$ acréscimo na entrelinha inferior ilegível;

20. $[\downarrow\{\} / \backslash]$ acréscimo na entrelinha inferior riscado e substituído por outro na sequência;

21. [* $\uparrow]$ parte do texto localizada à margem superior indicada pelo autor através de seta, linha ou números remissivos;

22. $\left[{ }^{*} \downarrow\right]$ parte do texto localizada à margem inferior indicada pelo autor através de seta, linha ou números remissivos;

23. $[* \rightarrow]$ parte do texto localizada à margem direita indicada pelo autor através de seta, linha ou números remissivos;

24. [* $\left.{ }^{*}\right]$ parte do texto localizada à margem esquerda indicada pelo autor através de seta, linha ou números remissivos; 
25. [*(f. ou p.)] parte do texto localizada em outro fólio ou página indicada pelo autor a partir de números e letras remissivos ou anotações. Nesses casos, o número do fólio ou da página aparecem entre parênteses;

26. /* / leitura conjecturada;

27. ( ) intervenção do editor (acréscimos e informações).

\section{RESULTADOS E DISCUSSÃO}

A primeira atividade realizada foi a organização do arquivo digital do corpus. Depois disso, foi realizada a conferência da descrição do caderno Diário de um João Ninguém e do caderno Lágrimas. Em seguida, observou-se as condições materiais dos manuscritos dos cadernos, a quantidade das folhas, a variedade de textos e a datação deles.

O caderno Diário de um João Ninguém é composto por 70 folhas, escritas no reto e no verso, com 22 pautas cada. Comportam no referido caderno poemas, rascunhos de cartas a amigos, políticos e outras autoridades, crônicas, cordéis, cópias de poemas de escritores conhecidos e anotações diversas. Os textos foram escritos entre os anos de 1977 e 1978. Em sua maioria, possuem emendas e rasuras. Na folha 1r, por exemplo, é apresentado um telegrama com duas datas distintas. A primeira data revela que o telegrama foi transcrito do "Jornal da Bahia", de 25-11-1976, já na segunda data, a transcrição foi escrita a caneta vermelha com uma possível correção: "os jornais trazem declarações de Ângelo Mário negando ser o autor do telegrama supra”, 26-11-1976. Notou-se também registros de textos com inclinações religiosas, com particularidades culturais da Bahia, tanto do interior quanto da capital, com características amorosas e particulares do escritor Eulálio Motta. Destaca-se um fac-símile e a edição da folha 6 reto, que se trata de um poema no qual o autor aborda sobre as perseguições da memória:

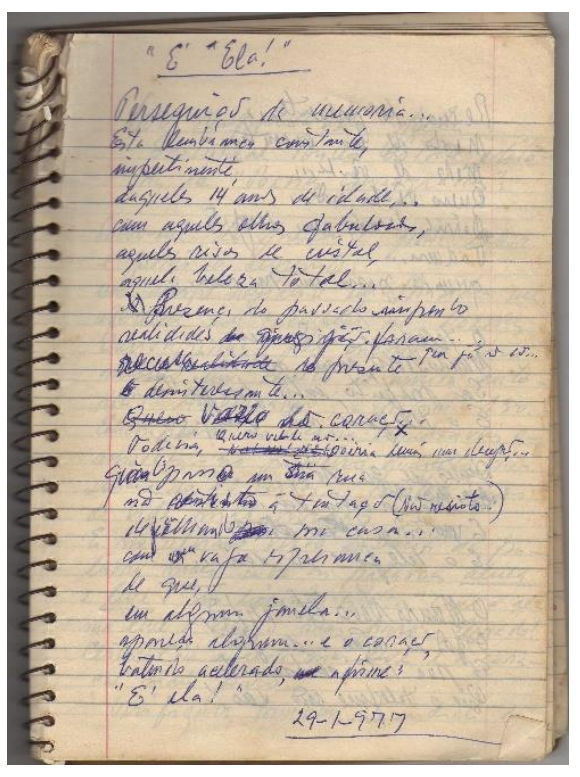

"É Ela!"

f. $6 r$

Perseguição de memoria...

Esta lembrança constante,

impertinente,

5 daqueles 14 anos de idade...

com aqueles olhos fabulosos,

aqueles risos de cristal,

aquela beleza total...

\{A\}Presença do passado impondo

10 realidades de que já foram...

\{recusa\} \{realidade\} do presente [१que já $\{\uparrow\}$ ]

desinteressante...

\{Quero $\}\{$ vazio $\}$ de coração...

Todavia, [ $\uparrow$ Quero $\{\dagger\}$ não....] /*Doiria/ /*demás/ uma decepção...

$15 / *$ quando/ passo em $\{$ sua $\}$ rua não \{resisto $\}$ à tentação ( Não resisto...)

definhando em casa...

com uma vaga esperanca

de que,

20 em alguma janela...

apareças alguem... e o coração,

batendo acelerado, afirme: 
Já o caderno Lágrimas contém 57 folhas, escritas no reto e no verso. Os textos foram escritos a caneta de tinta azul, preta, vermelha e a lápis. Em algumas folhas foram colados recortes de jornais e revistas com poesias de Eulálio Motta. As demais, são manuscritos com 30 narrativas: 21 poesias, 27 sonetos 6 rascunhos de cartas. Nesse caderno, há textos com registros do cotidiano do povo mundonovense, ditados populares, reflexão referente aos estudantes do curso de direito que estudavam no Ginásio Ipiranga entre outros. Além disso, Eulálio Motta registra algumas experiências que ele teve enquanto estudante na Faculdade de Medicina da Bahia.

\section{CONSIDERAÇÕES FINAIS}

Este trabalho teve por objetivo realizar a conferência da transcrição dos cadernos Diário de um João Ninguém e Lágrimas do escritor Eulálio Motta. Desse modo, corrigindo os possíveis erros de transcrição dos textos dos cadernos, deu-se confiabilidade tanto a pesquisa filológica quanto contribuiu-se para o tratamento filológico da documentação do acervo do escritor. Além disso, vale ressaltar que o trabalho de conferência de transcrição possibilitará que os leitores tenham acesso a eloquência escrita de um autor do século XX. Eulálio Motta, tinha o hábito de revelar os seus ideais através da competência escripta. Portanto, a transcrição realizada representa a perspectiva de trazer à tona um escritor não canônico, gerar outros estudos científicos e alimentar o sistema de banco de dados eletrônico do Núcleo de Estudos Interdisciplinares em Humanidade Digitais (NeiHD).

\section{REFERÊNCIAS}

BARREIROS, L. S. Bahia Humorística: causos sertanejos de Eulálio Motta. Feira de Santana: UEFS Editora, 2016.

BARREIROS, P. N. O pasquineiro da roça: edição dos panfletos de Eulálio Motta. 386f. Tese (Doutorado em Letras) - Instituto de Letras - Universidade Federal da Bahia, Salvador, 2013.

BARREIROS, L. L. S; TELLES, C. M. Riscos e rabiscos: estudo lexical de manuscritos éditos e inéditos de Eulálio Motta. In: ABBADE, C. M. S.; BARREIROS, L. L. S.; DOURADO, L. M. A.; BARREIROS, P. N. Filologia e estudos do léxico. Feira de Santana: UEFS Editora, 2018, p. 154.

CAMBRAIA, C. N. Introdução a crítica textual. São Paulo: Martins Fontes, 2005.

CARVALHO, R. B. S. A Filologia e seu objeto: diferentes perspectivas de estudo. Philologus. Círculo Fluminense de Estudos Filológicos e Linguísticos, ano, 2003, vol. 9.

$<$ https://edisciplinas.usp.br/pluginfile.php/34765/mod_resource/content/1/CARVALHO _RosaBorges_FilologiaEseuObjeto.pdf>. Aceso em: 15 mar. 2019.

TELLES, C. M. Léxico e edição semidiplomática. In: SELLA, Aparecida Feola; CORBARI, Clarice Cristina; BIDARRA, Jorge (org.). Pesquisas sobre o léxico: reflexão teórica e aplicação. Campinas (SP); Cascavel (PR): EDUNIOSTE, 2012, p.137- 158.

SPINA, Segismundo. Introdução à edótica: crítica textual. 2. ed. rev. e atual. São Paulo: ArsPoetica/EDUSP, 1994. 